\title{
Aboriginal Gambling and Problem Gambling: A Review
}

\author{
Helen Breen • Sally Gainsbury
}

Published online: 11 August 2012

(C) Springer Science+Business Media, LLC 2012

\begin{abstract}
The prevention of gambling-related problems amongst Aboriginal communities has been neglected by most public health strategies which concentrate on mainstream populations. Research indicates that rates of problem gambling are higher for Aboriginal groups than the general population. Specific cultural, familial, and social patterns influence gambling by Aboriginal groups, which are individually different, making it difficult to implement a cohesive strategy to address gambling-related harms. Because of this complexity, a thorough literature review is necessary to identify gaps in policy and research. This paper uses a public health framework to consider multi-dimensional influences (personal, environmental, economic, cultural and social) that affect gambling uptake. Such analysis is also important for identifying risk factors which facilitate the development and maintenance of problem gambling and potentially for underpinning protection, prevention and treatment programs. It is advised that strategies be developed in consultation with Aboriginal peoples to guide public health policy and research to minimise any gambling-related harms.
\end{abstract}

Keywords Gambling $\cdot$ Aboriginal $\cdot$ Indigenous $\cdot$ Culture $\cdot$ Risk factors $\cdot$ Public health

Many countries have been colonized by others in search of resources. The impacts of colonization for most Aboriginal people have permanently altered their society (Edmonds 2010). Colonization has impacted on abiding connections to land, ancestors and spiritual beliefs that underpin Aboriginal physical and cultural wellbeing (Dyall 2010). Wellbeing is also connected to social, environmental and economic factors (International Work Group for Affairs 2008; National Aboriginal Health Strategy Working Group 1989). Games of chance and gambling formed an integral part of the cultural, spiritual and economic landscapes of many Aboriginal societies before colonisation in North America (Belanger 2011; Binde

H. Breen $(\bowtie) \cdot$ S. Gainsbury

School of Tourism and Hospitality Management, Centre for Gambling Education and Research, Southern Cross University, PO Box 157, Lismore 2480 New South Wales, Australia

e-mail: helen.breen@scu.edu.au 
2005; Culin 1907; McGowan et al. 2001). However, for some Aboriginal societies, Māori in New Zealand and some Aboriginal groups in south-east Australia gambling was introduced by colonists (Breen 2008; Dyall 2010). Aboriginal societies evolved and adapted to colonial and then post-colonial governments. At the same time gambling participation altered. The legalisation of many forms of gambling, particularly commercial gambling (table games, electronic, online gambling) has broadened opportunities for all people, including Aboriginal people, to gamble. Like most people, Aboriginal people who gamble are subject to the accompanying benefits and harms of gambling. But as Aboriginal welfare is closely tied to cultural wellbeing, these benefits and harms seem likely to affect Aboriginal people in distinctive yet complex ways.

Research in several former British colonies, the United States of America (US), Canada, Australia and New Zealand reveals that various Aboriginal groups have a higher gambling involvement and higher prevalence of problem gambling than the general population (Alegría et al. 2009; Belanger 2006; Conner and Taggart 2009; Dyall 2007; Ministry of Health 2009; Petry et al. 2005; Stevens and Young 2009b; Walker et al. 2012; Williams et al. 2011). Some Aboriginal groups experience gambling problems three to four times higher than the general population (Volberg and Abbott 1997; Williams et al. 2011). North American Aboriginal peoples are estimated to experience gambling problems at about 2-3 times higher than the general population (Belanger 2011; Wardman et al. 2001). Similarly, Stevens and Young (2009b) reported a national gambling prevalence rate for Australian Aboriginal gamblers as $13.5 \%$. Although limited to secondary analysis of one gambling question in a health survey, this rate is about six times higher than that of the general population. Māori and Pacific Island peoples living in New Zealand are also at-risk for developing problem gambling, estimated at about four times that of the general population (Ministry of Health 2009, 2010). Recognizing harmful gambling outcomes, some responsible gambling and harm minimization campaigns have been designed and implemented using public health models (Ministry of Health 2010; Responsible Gambling Council 2011; Productivity Commission 2010). However few culturally viable public health options have emerged to assist Aboriginal gamblers in identifying and ameliorating any gambling-related problems (Breen et al. 2011; Smith et al. 2011). One consequence is a likely increase in the difficulties faced by Aboriginal people with gambling-related concerns in seeking and obtaining appropriate assistance.

Aboriginal peoples are culturally different to many groups in Western society. Generally, they are determined to preserve their ancestral lands, identity and continued existence as peoples within their cultural patterns, social institutions and laws (United Nations 2009). This limits the extent to which sociological research conducted in non-Aboriginal populations can be transferred. Identity, kin relationships and community obligations affect gambling by some Aboriginal groups (Cozzetto and Larocque 1996; Dyall and Hand 2003; Oakes et al. 2004; Stevens and Young 2009a). For example, Pacific Island people living in New Zealand could be migrants or born in New Zealand but all may still identify culturally as Pacific Island people. However, little information exists to explain how cultural factors influence gambling behaviours (Steane et al. 1998). Existing research is limited due to small sample sizes and various methodologies resulting in research that is not generalisable (McMillen and Donnelly 2008; Williams et al. 2011). The use of a standardised problem gambling screen such as the Problem Gambling Severity Index (PGSI) within the Canadian Problem Gambling Index (CPGI) (Ferris and Wynne 2001) may not be appropriate, affecting estimates of gambling prevalence rates and subsequent research implications. Limited published knowledge about gambling and gambling-related problems affecting Aboriginal people raises challenges for policy makers, effective responsible gambling programs, 
gambling support groups, counsellors, and treatment providers. Some in-depth understanding of gambling issues experienced by Aboriginal people is required before appropriate strategic public health policies and research strategies can be developed to address these gaps.

This review aims to examine evidence relating to gambling and problem gambling within Aboriginal groups in the US, Canada, Australia and New Zealand. These countries were chosen to be included in this review as they are all former British colonies and have minority Indigenous populations who experienced discrimination and dispossession through being colonised. As Aboriginal groups differ both internationally and within countries, evidence for individual groups will be presented to consider the differences and similarities between these societies. A classic public health model, one often used to investigate interactions among the host, agent and environment (Korn and Shaffer 1999), will be used to examine risk factors associated with Aboriginal gambling, particularly those associated with cultural and social issues. Although some strategies for harm-minimisation are suggested, this review will contribute to synthesising documented research and potentially informing appropriate gambling policy direction and implementation.

Studies included in this review were obtained through a search for peer-reviewed articles from 1985 onward on PubMed, Google Scholar and ProQuest using the key words 'gambling', 'Aboriginal', 'Indigenous', 'Māori', 'First Nations' and 'American Indian'. An online and library search was also made for published peer-reviewed articles and academically-based, rigorously conducted and reviewed 'grey literature' including, prevalence studies, qualitative investigations, government reports, ethnographies, and conference papers using similar key words. Personal contacts provided further references.

Unless sourced differently, the term Aboriginal is used in this review to identify First Nations, Indigenous or Aboriginal peoples who originate in or identify with a particular nation and who have deep abiding connections to their land and ancestral culture (Dyall 2010). Where the term Aboriginal gambling is used it refers to the gambling behaviour of Aboriginal peoples (Yanicki et al. 2011). Gambling is usually described as risking something of value on the uncertain outcome of an event or a game determined by chance (Korn and Shaffer 1999). A risk factor is an influence or variable associated with increased risk and with a high probability of adverse outcomes (Thomas and Jackson 2004). Problem gambling is defined as experiencing difficulties in limiting money and/or time spent on gambling leading to significant adverse outcomes for the gambler, other people and the community (Neal et al. 2005). Pathological gambling is seen as being a more severe, maladaptive and persistent form of addiction based on a clinical diagnosis (American Psychiatric Association (APA) 2000). These definitions are based on Western gambling concepts however Williams et al. (2011:182) maintain that the construct of problem/pathological gambling has some cross-cultural validity for several First Nations groups in Canada.

\section{Public Health Concepts}

Applying public health models to analyse associations between factors influencing gambling and problem gambling provides the means for exploring multi-dimensional influences (personal, environmental, economic, cultural and social) that affect gambling uptake (Korn and Shaffer 1999). Such analysis is also important for identifying risk factors which facilitate the development and maintenance of problem gambling and potentially for underpinning protection, prevention and treatment programs (Perese et al. 2005; Thomas and Jackson 2004). A public health approach uses concepts and language that are meaningful and useful 
for explaining multi-dimensional influences. A classic public health model based on communicable disease control can be applied to analyse and explain gambling phenomena and its consequences. Elements within this model include a host (the person and individual factors which influence their gambling), the agent (gambling exposure and its influence), and the environment (physical, social and cultural settings) (Korn and Shaffer 1999). In disease analysis another element, the vector, is included as a transmitting organism between species. For gambling, the vector can be considered as money (Korn and Shaffer 1999). By identifying gambling influences and risk factors using a public health model, responses can be developed to reduce exposure to the agent and increase host resistance to exposure (Perese et al. 2005).

\section{The Host}

Most Aboriginal people gamble socially for recreation and leisure (Belanger 2006; McMillen and Donnelly 2008; Ministry of Health 2010). However, some engage in high risk gambling activities and experience gambling-related harms. It is useful to examine cultural and psychological factors to help explain high risk gambling engagement.

\section{Cultural Factors}

Conducive cultural beliefs and greater rates of gambling participation have been identified as potentially contributing to higher rates of gambling problems within Aboriginal populations in North America (Alegría et al. 2009; Williams et al. 2011). In their review, Raylu and Oei (2004) proposed that cultures that approve of gambling tend to have higher rates of problem gambling. Further, minorities and immigrants who experience acculturation difficulties might be prone to problem gambling. Additionally, individuals from minority groups are less likely to seek help for problems with their gambling and untreated problem gamblers then have more gambling difficulties (Raylu and Oei 2004). Cultural factors appear to be linked to increased risks for some gamblers belonging to minority and Aboriginal groups.

Gambling among many North American Aboriginal people has been, and for some is still, a sacred and secular activity (Binde 2005; Culin 1907; McGowan et al. 2001). Sacred aspects of gambling are embedded in traditional myths, spirits, ceremonial observances, ritual practices, religious ceremonies, control over natural events (rain, harvest), and healing rites in order to influence outcomes (Gabriel 1996). Benevolent spirits are expected to help the gambler win, while mean spirits obstruct the same. Secular aspects of gambling include entertainment and winning (Gabriel 1996; Salter 1979). Winning brings a sense of honor and prestige. Wagers of valuable objects have ceremonial and economic value (Binde 2005). Gambling outcomes are perceived to be influenced by supernatural forces but these forces can also be controlled by man (McGowan et al. 2001). For example, Blackfoot traditional spirituality and good luck medicine has been used by a few Blackfoot problem gamblers to assist their chances of winning (McGowan and Nixon 2004). Cultural beliefs can also be used to address gambling problems. A rediscovery of genuine spirituality and authentic ceremony participation has assisted Blackfoot gamblers in their recovery (McGowan and Nixon 2004).

For Aboriginal Australians traditional card gambling is seen in different communities, often single and remote, as being connected to cultural values of autonomy and kin relationships (Altman 1985; Martin 1993) and tied to traditional practices of money redistribution (Goodale 1987; Hunter 1993). Money distribution gives the provider identity, social rank 
and prestige and involves reciprocal obligations for the receiver. Based on spiritual and luck associations (McDonald and Wombo 2006; Young et al. 2007), magic (Altman 1985); lucky charms, and potions (Martin 2008), are sometimes seen as being linked to large wins. However, asking these forces for help to win could be treated as cheating (Goodale 1987). Martin (2008, p. 84) noted that a belief in luck required "a concentration of mind, a single mindedness of purpose and a willingness to throw caution to the winds". Thus, a lucky card player was regarded as a highly skilled risk-taker. Card gambling is seen as a culturally constituted practice (Queensland Department of Corrective Services 2006) and represents some Aboriginal cultural beliefs.

New Zealand's history of Aboriginal people's gambling commenced with gambling by visiting sealers and whalers in the early nineteenth century. From its colonization by Britain in 1840, gambling has prospered in New Zealand (Dyall 2007). Traditional forms of gambling such as cards and housie are used to support Aboriginal cultural practices. Some Māori women in Rotorua ensure the cultural transmission of family histories by engaging in gambling at home (Morrison 1999). Many of these women had been socialised into gambling as children and believed that the money gambled remained in their social network. Further they said they had their own strategies to enable them to stop or modify any problematic gambling behaviour (Morrison 1999). Pacific Islander mothers living in New Zealand who participated in traditional activities such as customary gift giving were more likely to gamble than those who did not (Bellringer et al. 2006). For them, gambling was seen as a social activity and a means of sharing winnings among a community of gamblers or family members. Within the Pacific Islander group, Tongan people were more likely to gamble than those of other Pacific cultures (Bellringer et al. 2006). Gambling activities sometimes helped fund whanau (extended family) with the cost of fa'alavelave (customary financial support for weddings, events, church) and tangihanga (funeral) (Tse et al. 2012). As a respectful Māori tradition, tangihanga strengthens kinship loyalties and facilitates intergenerational transmission of cultural history and values (Dyall 2007), while fa'alavelave has similar meanings in Samoan traditions (Tse et al. 2012).

Investigating cultural strength and its influence on gambling in Edmonton Alberta, Currie et al. (2008) conducted a mixed methods project with 60 First Nation university students. The theory of biculturalism was used to explore the degree to which this group saw their mainstream and First Nation cultural identities as being compatible or integrated. A highly integrated sense of cultural identity indicated high biculturalism, which was associated with lower levels of problem gambling. In contrast, poor negotiation between two cultures with integration difficulties and oppositional relationships indicated low biculturalism, which was associated with problem gambling and seems to be a risk factor for these gamblers. Cultural exposure and flexibility by high bicultural students appeared to offer some protection against problem gambling and increase their social inclusiveness.

Aboriginal cultural traditions appear to have profound historical, secular and sacred connections to gambling for some groups. These connections support Raylu and Oei (2004) and Williams et al. (2011) that conducive cultural beliefs, high rates of gambling participation and endorsement of gambling tend to be associated with higher rates of gambling problems. The extent to which gambling is endorsed seems to depend on cultural norms, such as the important role of passing on and maintaining traditional ceremonies, history and customs, meeting reciprocal obligations, beliefs in winning, luck and skill, and adaptation to new experiences that are distinctive to particular Aboriginal societies.

Additionally, these cultural factors may contribute to a belief in skill and luck in winning with commercial gambling. Gambling products such as poker or slot machines have been designed to produce random outcomes even when programmed and presented to make skill 
and luck appear to influence the outcomes (Parke and Griffiths 2007). Although some traditional Aboriginal gambling includes skill and choice, for commercial gambling, the longer a gambler plays, the more they are likely lose. Regular, lengthy gambling sessions on commercial gambling and long-held beliefs about gambling skill and choice are strongly associated with problematic gambling (Joukhador et al. 2003, 2004). Therefore, high gambling participation rates interwoven with family support, respect for kin, beliefs about winning, and cultural transmission motivations seem to be associated with higher risks of gambling problems for some Aboriginal people. To preserve the positive and protective aspects of cultural traditions, public health and research strategies should aim to identify the cultural significance of gambling within Aboriginal communities. Simultaneous efforts are required to raise awareness and educate communities of culturally appropriate ways to gamble and risks associated with commercial gambling.

\section{Psychological States and co-Morbidity}

Psychological issues underlying problem gambling usually involve variations in the gambler's mood, mental health, and alcohol and substance use. In qualitative interviews with five self-reported problem gamblers of the Blackfoot Nation, McGowan and Nixon (2004) found that as gambling escalated and financial difficulties increased, their mood swings, guilt and shame also increased. In Alberta, Currie (2007) found that First Nation problem gamblers (using the PGSI) were less happy and felt isolated. They smoked more cigarettes while gambling to try to control negative emotions caused by gambling. In New Zealand, where being of Māori and Pacific ethnicity is significantly associated with problem gambling, the Ministry of Health (2009) concluded that problem gamblers are more likely to be daily smokers, have hazardous alcohol consumption, have worse self-rated health, and have a high probability of a mood or anxiety disorder. Also in New Zealand, Penfold et al. (2006) reported that problem gambling patients admitted to hospital following a suicide attempt were more likely to be Māori and more likely to have alcohol problems.

People with prior addictions and/or mental health disorders are often at risk of developing gambling problems (Petry et al. 2005). From a national survey of 43,093 people in the US, Alegría et al. (2009) report that Native Americans have a significantly higher prevalence of disordered gambling $(2.3 \%)$ compared to the general population $(1.2 \%)$, and also experience greater mental disabilities. With over 1,200 Aboriginal veterans in the US, Westermeyer et al. (2005) found that substance abuse, mood swings and antisocial personality disorders were associated with pathological gambling. Aboriginal veterans suffering from DSM-IV Axis I disorders were 2-3 times more likely to be diagnosed as pathological gamblers. The authors concluded that this population had a $70 \%$ chance of lifetime comorbidity of psychiatric disorders and recommended early intervention for pathological gambling (Westermeyer et al. 2005).

In Québec and Labrador, a regional health survey of 4,000 First Nations adults selfassessed problematic social issues for their families. After alcoholism, drug use, and verbal/ psychological abuse, gambling problems were ranked as the fourth most significant problem. These adults had experienced minor (14\%) and major (7\%) gambling-related problems. Although no gambling screen was used, the reported proportions of gambling-related problems were higher than that of the general population (First Nations of Québec and Labrador Health and Social Services Commission [FNQLHSSC] 2006).

After consulting with 98 Aboriginal and non-Aboriginal Australian health and welfare officers in nine regional and urban centres in New South Wales (NSW), the Aboriginal Health and Medical Research Council (AHMRC) (2007) identified major risks associated 
with problem gambling as stress, anxiety and substance misuse. In their review, McMillen and Donnelly (2008) described drug, alcohol, and social marginalisation problems as being linked with Aboriginal problem gambling. They concluded that gambling helps some people cope with negative feelings of being unable to fully participate in society (McMillen and Donnelly 2008). Thus, links between varying psychological states, co-morbidities and gambling suggest a compounding of risk and stress.

\section{Stress}

Gambling at increasingly higher levels may help people cope with stress and negative life events (Blaszczynski and Nower 2002; Jacobs 1986; Korn and Shaffer 1999). An important motivation for some Aboriginal gambling is reported to escape from stress and problems or to cope with difficult lifestyles (Dion et al. 2010; Dyall 2007). New Zealand research with 209 people of mixed ethnicity reported that gambling to escape from stress increased for problem gamblers but not for non-problem gamblers from initiation to their continuing gambling (Clarke et al. 2007). Stress appears to be a catalyst for some high risk gambling involvement.

Pathological gambling may be a learned defence to escape, dissociate or relieve stress from childhood trauma (Dion et al. 2010). First Nation Canadians removed from their families as children to live in residential schools have reported grief and loss as a result of childhood abuse, loss of parental care, and loss of traditional cultural practices (Hewitt 1994; Tonmyr and Blackstock 2010). In a review of 13 child sexual abuse studies, two conducted with First Nation Canadians, pathological gambling was said to be a maladaptive coping strategy to avoid abuse-traumatic memories (Dion et al. 2010). Similarly, in Australia, the AHMRC (2007, p.12) noted "grief and loss were often identified as contributing factors to gambling for Aboriginal people”. From qualitative interviews with 60 Aboriginal Australians in Queensland (QLD), living with grief and loss from the death, suicide and incarceration of family and community members is reported to contribute to some committed high risk gambling (Breen 2012b). Dyall (2004, 2007, 2010) argues that stressful living conditions and dispossession experienced by Māori people as the original people of the land (tangata whenua) underpins much of their generally poor health, depression, substance abuse, crime, incarceration, suicide, and increasingly high risk gambling. The stress of living with inequity, grief and loss was seen as contributing to gambling in problematic ways.

Importantly, research results from Westermeyer et al. (2006) found that an absence of stress appeared to be related to a reduction in gambling. In a sample of over 1,600 Aboriginal veterans in the US, remission from a lifetime diagnosis of problem gambling (no gambling symptoms in the past year), using the Diagnostic Interview Schedule for DSM-III-R (APA 2000), was associated with a lack of stress and post traumatic stress (Westermeyer et al. 2006). Stress appears to be closely bound to initiating and maintaining problem gambling for some Aboriginal gamblers and an absence of stress appears to reduce this risk. Relieving stress through alternatives may modify some problematic gambling.

Some Aboriginal groups experiencing high rates of gambling-related problems have common histories of colonization and dispossession. Alongside gambling problems, other risks include physical and mental health problems and social concerns (Perese et al. 2005). Their review indicates that varying psychological states, including stress, grief and loss, comorbid mental disorders, such as depression, high alcohol, and drug use, and social isolation are often related to, or underlying high-risk gambling. These risk factors appear to play a role in the development and maintenance of problem gambling. Resources dedicated to screening 
those in treatment for problem gambling and for psychological disorders may help in identifying early intervention strategies appropriate for Aboriginal groups in need of further assistance. Efforts to assist communities to develop healthy coping skills to manage negative emotions may also reduce gambling-related harms.

\section{The Agent}

The agent, gambling exposure and its influence, is made up of, but not limited to, the physical availability of gaming products and services (Korn and Shaffer 1999), societal modeling, gambling depictions in the media, myths about winning (Williams and Simpson 2008), the gambler's environment, the acceptability of gambling, the increasing globalization of gambling, and gambling technologies (Perese et al. 2005). Thus, a mix of influences can underpin gambling decisions. Decisions about using gambling products can depend on features and marketing which enhance their appeal.

\section{Gambling Products and Services}

Greater exposure, access, and availability of any gambling product or service usually means greater use of that product or service (Williams and Simpson 2008). Greater use of some products and services, such as continuous gambling, usually means higher gambling involvement and sometimes higher risks. For people who just use lotteries and instant scratch tickets weekly, their gambling risks are usually low. However for people who use continuous gambling products weekly (table games, wagering or poker machines), their gambling risks rise sharply (Productivity Commission 2010). Regular weekly gamblers who prefer continuous forms usually play at higher intensities and for longer sessions than other less regular gamblers.

In the US, increased exposure and ready access to casino gambling was said to encourage high rates of pathological gambling for both female and male Aboriginal veterans (Westermeyer et al. 2005). Similarly, in five Canadian Aboriginal communities and using focus groups, Wynne and McCready (2005) found that gambling was easily accessible and popular; especially lottery and instant win tickets. Gambling expenditure ranged from about CAD \$40 per month to CAD\$300 at a single session, with an average spend at the lower end. Problem gambling (using the CPGI) was up to $19 \%$. Higher rates of problem gambling were found in communities where casinos and Video Lottery Terminals (VLTs) were readily available. People in these communities experienced the most adverse gambling consequences (Wynne and McCready 2005).

Traditional and modern forms of gaming are available North America on some First Nations land, both owned and operated by First Nations people. Hand (stick) games, horse racing, bingo, VLTs, casino gambling, lottery and instant scratch cards are popular (McGowan and Nixon 2004). In north Québec, research with Cree people found VLT's to be the very popular, followed equally by bingo, instant win tickets and lottery. Adults travelled long distances for casino gambling and engaged in casino gambling as much as their southern counterparts (Papineau 2009). Therefore, if a preferred form of gambling is not available, people may incorporate gambling into their travel plans.

Easy gambling access in disadvantaged neighbourhoods was reported to be an important factor contributing to Aboriginal problem gambling in New Zealand (Ministry of Health 2009). Low income groups living in disadvantaged suburbs usually include many Māori and Pacific people (Walker et al. 2012). Tse et al. (2012) maintain that people in deprived areas 
are targeted by a high concentration of poker machines and that ease of playing poker machines facilitates their use. High gambling participation rates due to frequent continuous gambling by Māori and Pacific people results in higher levels of gambling harm for them and their significant others (Walker et al. 2012). Of those other affected people, $25 \%$ were themselves at some risk with their gambling or were actually problem gamblers. Poker machines in casinos (33\%) and in non-casino venues (53\%) were preferred gambling forms (Ministry of Health 2009). For non-casino venues, gambling availability in shopping centres, hotels, clubs, and family restaurants, meant that access was open despite legal age restrictions (Tse et al. 2012).

In Australia, Aboriginal gamblers were found to prefer poker machines, followed by, TAB or pari-mutuel gambling, keno and bingo (Dickerson et al. 1996). Generally, men preferred $\mathrm{TAB}$ gambling on racing and sports events, while women preferred poker machines, bingo, and traditional cards (Breen et al. 2011). Despite Dickerson et al. (1996) reporting young Aboriginal males more at risk with their gambling, others found Aboriginal women to be more at risk (McMillen et al. 2004; Stevens and Young 2009b). For the Northern Territory (NT), increased funds (e.g. mining royalties) and growing availability of gambling has resulted in increased gambling with a reported problem gambling rate of $24 \%$ for Aboriginal Australians (Stevens and Young 2009a).

Using qualitative methods, Breen et al. (2011) interviewed 169 Aboriginal and 31 nonAboriginal Australians (21 gaming venue managers, 10 gambling counsellors) finding risks associated with gambling as physical and sensory experiences, emotional ties to 'lucky' poker machines, and ease of use. Physical and sensory experiences included the sound, light, and visual features of poker machines and their attractive marketing and promotion (Breen et al. 2011). In a different qualitative project with 60 Aboriginal Australians, Breen (2012a) identified risks linked to traditional card games as generational exposure, use of traditional exchanges (goods, favours), and ignoring cultural norms.

For internet gambling, Wood and Williams (2009) found that being a Canadian and having Aboriginal ancestry significantly increased the odds of being an Internet gambler by 3.9 times. Risks of internet gambling uptake by Aboriginal people have not been adequately investigated, however, Tse et al. (2012) warn that use of internet, text-messaging, and tollfree phone number gambling provides open access which is difficult to control. Drawing on this research, gambling risk factors include exposure, access, availability, custom, and an attachment to a preferred form of gambling, usually continuous gambling. Gaming venues are typically required by law or a voluntary code of conduct to implement host responsibility and responsible gambling strategies. These would benefit from the inclusion of cultural considerations for Aboriginal people who choose to gamble.

\section{Gambling Marketing}

In Canada, New Zealand, and Australia some community organizations operate gambling activities (Dyall 2007; Hing et al. 2002; Papineau 2009). These community organizations play a redistribution role in funding or subsidizing food banks, health and welfare services, local associations, sports tournaments, schools, daycare centers, and the like. In Canada, community operated gambling (bingo, instant lotteries, and various types of draws) is generally considered to be mutually beneficial in contrast to state-run commercial gambling, such as VLTs, which represent a net community loss (Papineau 2009). Yet, findings from a qualitative study with 44 health and social services workers in Cree communities suggest that having both state and community gambling activities available not only increased gambling access but also legitimized or endorsed gambling. Gambling had grown into a 
major leisure activity and gambling profits, which underwrote community development, resulted from high risk gambling by some Cree people. People who had accumulated large gambling debts were being shouldered by their entire family (Papineau 2009). Gambling problems were seen here as being perpetuated.

In New Zealand, Dyall (2007) maintains that gambling funds underwriting community events and infrastructure endorse gambling when publicised. Those in receipt of gambling grants were encouraged to place gambling-related logos on their uniforms, buildings (marae or meeting places) and Kohanga Reo (Māori early childhood centers). Additionally, Dyall et al. (2009) contend that Māori artwork and culture are exploited in marketing gambling. The overt use of the Māori poi on poker machines, Māori carvings in gaming venues, and Māori Elders being invited to open gaming venues with traditional rituals seemed to promote gambling as a safe Māori activity, one associated with cultural and spiritual values (Dyall et al. 2009). In a survey on awareness and attitudes towards gambling advertisements with 1,500 New Zealanders, Māori people had a higher recall for race track betting advertisements than non-Māori . Pacific Island people had a higher recall for casino messages than the general population (Abbott and Volberg 2000). Gambling advertising appears to influence gambling participation amongst Māori and Pacific (Samoan, Tongan) peoples which Dyall (2007) argues mirrors the prevalence of their gambling problems.

Although using gambling activities to raise funds for socially-relevant projects may be intended to benefit Aboriginal communities, the potential for negative consequences exists. Such fund raising may be perceived to encourage gambling by Aboriginal people, creating further gambling risks. Similarly cultural symbols used to endorse gambling activities may also be perceived to encourage Aboriginal gambling and for some, become a risk factor for heavy gambling. Socio-economic analyses could be conducted and publicly reported to examine community costs and benefits from gambling operations. Such analyses may be activated by Māori within their rights under the Treaty of Waitangi and the United Nations Declaration on Rights for Indigenous Peoples (Dyall et al. 2012). This treaty is an example of how Indigenous people can take an active and leadership role to influence gambling policy that impacts them. Again Māori action could influence legislation and industry codes of conduct to restrict marketing of cultural representations associated with gambling. In general, public health policy should ensure that gambling benefits outweigh any costs and genuine efforts are implemented to protect individuals and Aboriginal communities.

\section{The Environment}

Environmental factors including familial, community and residential contexts influence gambling participation. Although familial factors could be discussed within the host, it is included here as familial and community issues are interwoven in many Aboriginal societies.

\section{Families and Friends}

Gambling activities can be a part of everyday life. Although generally considered to be a form of socialising, gambling in families and with friends can lead to risks. Family risks may include high exposure to gambling (Bertossa et al. 2010), generational gambling, transgenerational learning about gambling, and normalisation of youth gambling (Breen et al. 2011). Family problems arising from high risk gambling can include absence and neglect, marriage/family problems, abuse and violence, and isolated children (Schulter et al. 2007; Williams et al. 2011). In contrast, strong family influences and values, sharing alternative 
interests and time with family and friends outside gambling, positive relationships, and adequate education have been found to be protective factors against gambling problems (Breen et al. 2011).

Parental gambling behaviour affects children. Intensive parental gambling may contribute to low family income and financial hardship (Hewitt 1994; Walker et al. 2012), a lack of appropriate child care (Peacock et al. 1999), neglect, stress, arguments, and relationship difficulties (Wātene et al. 2007). In a Canadian review of Aboriginal gambling, Papineau (2009) described Quebec leaders in Iiyiyiu Aschii being concerned about gambling spending outweighing food purchasing, child neglect, declining participation at citizen meetings, and family breakups caused by gambling. In support, Schluter et al. (2007), using quantitative methods, found that poor nutrition, housing difficulties, and absence were related to gambling by young, mostly single Pacific Island mothers living in Auckland, who gambled to supplement their social security payments. Similar findings were reported from focus group meetings across six regions of New Zealand by Wātene et al. (2007). People from minority groups with disadvantaged backgrounds may place a higher value on winning than the general population and see losses as less adverse outcomes. The differential value of risk may lead to an increased willingness to gamble, and for some, increasing gambling problems (Alegría et al. 2009). The relationship between Aboriginal problem gambling and poverty is well documented and related to the quality of life for children and families (Ministry of Health 2009; Walker et al. 2012; Wardman et al. 2001; Williams et al. 2011). In contrast, the removal of poverty, whatever the cause, appears to have long-term positive consequences for children (Costello et al. 2003).

In Australia, Delfabbro et al. (2005) conducted a school-based study of gambling with 926 students aged 13-18 years, including 32 Aboriginal youth, using a combination of gambling screens. Aboriginal students gambled more than others and comprised a large proportion of the problem gamblers. More problem gamblers $(90 \%)$ said that their parents gambled compared to their peers $(71 \%)$. Students with gambling problems were more likely to have impoverished personal relationships, be poorly adjusted and socially alienated. Their friends were much more likely to gamble and approve of gambling than others (Delfabbro et al. 2005). However, the small sample size reduces the extent to which conclusions can be drawn from this research.

Friends can encourage or discourage gambling. Some US Aboriginal veterans gambled because of encouragement from friends, neighbors and peers, with some reporting that they first gambled while in the military (Westermeyer et al. 2008). In Currie's (2011) research with 381 Aboriginal participants in Edmonton where $33.3 \%$ were found to be problem gamblers using the CPGI, $30 \%$ of participants believed that their parent had a current gambling problem, and $30 \%$ reported being negatively impacted as a child by their parents gambling, due to financial strain and neglect. Almost all participants had a relative or friend with gambling problems, adding to their stress.

It appears that other close gamblers may heavily influence an individual's gambling decisions, including high risk decisions, and also negatively impact non-gamblers. Local cultural networks should be made aware of signs of gambling and problem gambling to try to minimize the impact of other people's gambling. Education is needed to increase awareness of sources of help for those affected by another person's gambling, including culturally sensitive and relevant sources of help. Public health policies should aim to assist communities to support gamblers and their friends and family with appropriate information, education and resources.

\section{Gambling by Adolescents}

Problem gambling during adolescence can lead to strained relationships, delinquency and criminal behaviour, depression and even suicide (Derevensky and Gupta 2004; Derevensky 
et al. 2004). In the US, Stinchfield et al. (1997) compared rates of gambling in 1992-1995 with 122,700 Minnesota public school students between grades 6-12. Gambling frequency was higher for all cultural minority groups including Native American students. Similar results were found by Peacock et al. (1999) on a Great Lakes Native American reservation, comparing gambling activities of 185 adolescent Aboriginal and non-Aboriginal Americans in grades 7-12 in one tribal and one public school. Statistically significant relationships were found between gambling habits, parental gambling, high-risk behaviours and low selfesteem for Aboriginal students. In Alberta, using the SOGS instrument revised for adolescents, Hewitt and Auger (1995) surveyed over 950 Aboriginal adolescents and found that nearly $90 \%$ had gambled in the past year, approximately $28 \%$ were problem gamblers, and $21 \%$ were at risk of developing gambling problems. The problem gamblers lived both on and off reservations. They were more likely to engage in risky alcohol, tobacco, and drug use, sustain violent injuries, have property damaged, experience suicide and death within family and friendship circles, have school truant friends, and parents who gambled. Although Williams and colleagues (2011) have concerns about the validity of the revised SOGS instrument for adolescents, Canadian Aboriginal adolescents are more likely than other ethnic groups to score as problem gamblers when compared with their peers (Wynne Resources Ltd 1996). This finding is consistent with those of other studies of gambling amongst First Nations adolescents (Elia and Jacobs 1993; Zitzow 1996a).

Poverty is associated with adolescent gambling. In Saskatchewan, poor Aboriginal youth seem more vulnerable to risky behaviors including gambling compared to poor nonAboriginals (Schissel 2001). In a survey with 2,605 high school youth in urban and regional schools, Schissel (2001) found Aboriginal male youth who gambled frequently had low family incomes. Their high risk continuous gambling, particularly on VLTs, was significantly associated with high levels of disempowerment and drug and alcohol use. For Aboriginal Australian youth problem gamblers, Delfabbro et al. (2005) reported that the average age of gambling onset was lower than their peers. They typically had an early big win and their problem gambling was highly related to use of cigarettes, marijuana, and hard drugs. The authors speculated that their gambling may have been based in cultural exchanges or reflect hardship because of unemployment and poverty (Delfabbro et al. 2005). While gambling problems may be underestimated if students with gambling problems leave school at higher rates than their non-gambling peers (Wardman et al. 2001) these studies demonstrate that some younger and poorer Aboriginal youth experience higher risks with their gambling than their peer groups. Efforts could be taken to integrate gambling education into school curriculums, including culturally relevant materials. Early intervention programs in schools and communities may reduce gambling participation and related problems amongst Aboriginal youth. Strategies to educate teachers, school counselors and general practitioners about gambling risks may increase some recognition of adolescent problems and assist early intervention.

\section{Communities}

Gambling can contribute to social, political, cultural and economic life of Aboriginal communities but it can add to social, tribal and community vulnerabilities (Clay 2009; Yanniki et al. 2011). Cozzetto and Larocque (1996), in longitudinal research with Aboriginal communities in North Dakota, suggested that rising rates of pathological gambling increased community problems by adversely affecting tribal culture, social collectivism, and the role of Elders. Social dysfunction associated with gambling affected economic development by constraining partnerships and reducing infrastructure development. 


\section{Living on an Aboriginal Reservation or Community}

Gambling venues on First Nation reservations contribute much needed revenue and opportunities for sovereign control, land rights, and cultural preservation (Belanger 2010). The introduction of gambling can be seen as a step towards self-sufficiency, to lift communities out of "depressed socioeconomic situations" (Clay 2009, p. 62). Some benefits of reservation gambling include lower unemployment, reduced poverty, and improvements in social and cultural programs, plus improved health, welfare, and education levels (Conner and Taggart 2009; Momper 2010).

Despite beneficial effects from reservation gambling, increases in the availability of gambling usually bring a proportional increase in gambling-related problems (Abbott and Volberg 2000; Momper 2010) and in the mid-1990s Hewitt (1994) reported that just living on a reservation was perceived to encourage gambling. In research with 156 Alberta First Nations people who identified themselves as heavy gamblers, Hewitt (1994) found that about $95 \%$ experienced at least one significant gambling problem as well as economic and social problems. Gamblers living on the reservation often tried to increase their income with winnings (Hewitt 1994). A study by Zitzow (1996b), found that living on a reservation with low economic status, unemployment, high alcohol use, historical trauma, and a lack of social alternatives predisposed some Aboriginal people to risks of developing problem gambling.

Later, Williams et al. (2005) conducted a random household survey with 90 Aboriginal adults living on Kanai (Blood) Reserve in Southern Alberta. Using the CPGI to identify gambler groups, findings indicate that almost $40 \%$ were non-gamblers, about $10 \%$ were low risk gamblers, nearly $30 \%$ were moderate risk gamblers, and over $20 \%$ were probable problem gamblers. There was a higher rate of moderate risk and problem gambling compared to less than $10 \%$ in each group in the general population. Signs of problem gambling for this community included: addiction, obsession, broken homes, child neglect, alcohol abuse, and selling personal items. The majority of people (60\%) answering the entire survey $(n=216)$ reported that harm from gambling outweighed the benefits (Williams et al. 2005).

One concern about reservation gambling is its impact on traditional Aboriginal practices. Oakes et al. (2004) explain that of the 192 people they interviewed in several Aboriginal Ontario communities, $16 \%$ reported negative gambling effects for their community and traditions. For some, commercial gambling on reservations is perceived as replacing traditional Aboriginal lifestyles, activities and values with materialism (Dyall 2010; Peacock et al. 1999). This represents an assimilation of Aboriginal culture into Western culture (Momper 2010). In support, Williams et al. (2005) maintain that ceremonial gambling has been mostly replaced by commercial forms and that traditional gambling has largely been replaced by western forms.

Although there are no casinos in Australian Aboriginal communities some small remote communities are somewhat similar to North American reservations. In a remote region of Western Australia, Hunter and Spargo (1988) while conducting random health checks surveyed 192 Aboriginal people, finding $50 \%$ were card gamblers. Card gambling resulted in compromised nutrition, impaired parenting and higher anxiety scores for some. Opportunities for saving and for community development were limited through gamblers' dependence on funds from reciprocal sharing. Hunter (1993) argued that stress, anxiety and unpredictable economic circumstances were associated with problematic gambling in other, similar remote communities. Again, in remote Aboriginal communities, Hoy et al. (1997) conducted health surveys and found a range of community and environmental issues, including gambling, as contributing to the risk of illness. More recently, Stevens and Young (2009a) used secondary research to investigate Aboriginal gambling in the NT. Significantly higher gambling problems were reported for remote compared to non-remote areas. In 
remote areas, gambling problems associated with social transgressions (witness or involvement in abuse or violent crime, police contact, and alcohol and drug problems) were 2-3 times higher compared to the non-remote Aboriginal population and 3-10 times higher than the general population. In an unusual case an application for poker machines at a remote hotel in South Australia was refused because two small nearby Aboriginal communities were impoverished and at high risk of social problems. The potential for increased violence, antisocial behaviour and negative socioeconomic impacts were recognised (Brady 2004).

Living on an Aboriginal reservation or remote community has been identified as a risk factor for the development of gambling problems. The effects of gambling problems ripple through entire communities affecting many more than just the gambler. Further research is necessary to focus on precise factors that mediate the relationship between community settings and gambling problems. Potential strategies to minimize gambling harms include developing alternate activities and culturally-relevant support systems and networks to encourage social inclusion and offer protection to members from developing problems.

\section{Living in Urban Communities}

There has been a dearth of research investigating gambling by Aboriginal people living in urban areas. Many Aboriginal populations are demographically young and youthfulness influences gambling participation (Raylu and Oei 2004). In 2006, $54 \%$ of Aboriginal Canadians lived in cities and almost half the First Nations population was under 25 years (Statistics Canada 2008). Canadian Aboriginal people living in urban areas were more than twice as likely to live in poverty as non-Aboriginal people (Lee 2000). Of concern there is a greater proportion of younger, urban Aboriginal people represented in high-risk gambling groups (Canadian Council on Social Development (CCSD) 2011). Similar population patterns for Aboriginal people can be seen in the US, New Zealand, and Australia (Australian Bureau of Statistics (ABS) 2011; Ministry of Health 2010; US Census Bureau 2012).

Urban living with limited Aboriginal support may create stress, isolation, and feelings of dislocation for Aboriginal families (CCSD 2011). Using mixed methods, Currie (2011) surveyed 381 Edmonton people, of whom $75 \%$ were Aboriginal and $25 \%$ were Métis people. One in three were identified as problem gamblers using the CPGI; $15 \%$ had severe risks, and $18 \%$ had moderate risks (Currie, 2011). The major motivation for gambling (75\%) was to escape. Qualitative themes revealed that gambling provided escape from feelings of social alienation and low social cohesion (Currie 2011). About $43 \%$ had experienced public racial discrimination more than twice in the past year. This high level of racism had significant personal and cultural impacts, resulting in gambling to escape being used as a coping mechanism. Additionally, problem gambling was associated with significant psychological impacts, including severe depression $(50 \%)$, prescription drug dependence $(31 \%)$, and suicide ideation (12\%). Less than one in five $(18 \%)$ of the problem gamblers had sought help (Currie 2011). Similarly, interviews with 2,614 First Nations, Métis, and Inuit people living in 11 Canadian cities reported that many felt stigmatized by negative assumptions about addictions (75\%), laziness (30\%) and poverty (20\%) (Environics Institute 2010). Coping with racism may be a risk for developing gambling-related problems for urban Aboriginal groups.

A qualitative study with 131 people, broadly representative of Māori, Pacific, Asian, and Pakeha, found that changing to an urban lifestyle created stress and was linked to some people gambling intensely to escape or cope (Tse et al. 2012). For unemployed urban people needing money quickly to fulfill customary obligations can lead to stress and some high risk gambling, especially for Samoan people living in New Zealand (Tse et al. 2012). 
Australian Aboriginal gambling was investigated by Dickerson et al. (1996) with surveys with 222 Aboriginal people (103 women, 119 men) in two urban and two regional towns in NSW. About half the sample gambled weekly and they experienced significant negative gambling impacts. Nearly one-third of the participants reported family members as experiencing problems with their gambling, twice the rate reported by the NSW population. An evaluation of the introduction of poker machines into QLD clubs and hotels revealed that, in the city of Cairns, poker machines quickly became popular and gained favor over traditional card gambling (Australian Institute for Gambling Research and Labour and Industry Research Unit (AIGR/LIRU) 1996). In a convenience sample of 128 gamblers in venues, $78 \%$ preferred poker machine gambling and only $4 \%$ nominated cards. With average weekly gambling expenditure of AUD \$60, half was spent on poker machines. Before poker machine gambling was introduced, $29 \%$ had never gambled. Thus the expansion of commercial gambling was attractive for some Aboriginal people in urban areas. For NSW where commercial gambling had been available since the mid 1950s, problem gambling rates were higher for Aboriginal compared to non-Aboriginal people.

The small body of research on gambling and problem gambling amongst Aboriginal people living in urban communities indicates that there are specific risk factors related to this environmental setting. Although further research is necessary to explore the complex relationships between factors in more detail, negative emotions including stress, isolation, inequity and racism, appear to motivate Aboriginal people to gamble to escape and cope with these feelings. Coupled with greater availability of commercial gambling and a lack of community support and cohesion, the development and exacerbation of gambling problems affects individuals and their families. A public health policy framework would advocate the creation and implementation of culturally-relevant prevention and treatment programs. Resources should be available for those directly and indirectly impacted by gambling in urban communities.

\section{Conclusions}

This review has identified research directly and indirectly examining issues pertaining to Aboriginal gambling and problem gambling. Using a public health approach this review has analysed research results from Canada, the US, Australia, and New Zealand with various groups. It is clear that some Aboriginal people face both common and distinctive risks with their gambling. These risks need addressing to reduce adverse consequences for individuals, families, and the wider community.

Risk factors associated with the gambler or host appear to include cultural factors such as conducive customary beliefs, traditions and practices; endorsement of gambling from a historical perspective; gambling to meet traditional kin obligations regarding respect and support and for transmission of culture; and low biculturalism or an inability to easily adjust to living in a multi-cultural society. Other risk factors associated with psychological states of the host appear to be negative moods; feelings of social alienation; co-morbid disorders; high alcohol, drug and tobacco use, and elevated stress levels. High stress levels were reported to emanate from grief due to childhood loss, early loss of loved ones, and effects of societal inequity.

For the agent, risk factors surrounding gambling products and services are reported to include high exposure and availability in all locations but especially in deprived areas and easy access to preferred forms of gambling, particularly continuous gambling. For gambling marketing, risk factors seem tied to assumptions that community operated gambling has 
more beneficial effects than commercially operated gambling and that cultural endorsement is implicit when cultural symbols or figures are used with gambling products and services.

The environment (family, friends, communities and location) included high risks for some Aboriginal people who gamble. Risk factors appear to be family poverty and gambling to increase income; having parents and friends who gamble; being younger and engaging in risky behaviour with peers; living on a reservation or in a remote location where gambling was contributing to physical and social disadvantage as well as the loss of cultural philosophies and customary traditions; and living in urban areas where gambling opportunities were high, social deprivation was ubiquitous and racial discrimination practiced. These risk factors, along with proposed aims and potential strategies for modification of these risk factors can be seen in Table 1 .

Table 1 Aboriginal gambling risk factors, potential public health modifications and aims

\begin{tabular}{|c|c|}
\hline Risk factors & Potential modifications \\
\hline \multicolumn{2}{|l|}{ Host (Individual factors) } \\
\hline Cultural factors & $\begin{array}{l}\text { - In-depth knowledge on authentic } \\
\text { cultural traditions \& associated } \\
\text { obligations, }\end{array}$ \\
\hline $\begin{array}{l}\text { - Cultural traditions, } \\
\text { obligations that endorse } \\
\text { \&/or include gambling } \\
\text { activities, }\end{array}$ & $\begin{array}{l}\text { - Culturally relevant information \& } \\
\text { increased awareness about gambling } \\
\text { \& winning, }\end{array}$ \\
\hline $\begin{array}{l}\text { - Cognitive beliefs in levels } \\
\text { of luck \& skill involved in } \\
\text { gambling, }\end{array}$ & $\begin{array}{l}\text { - Increased knowledge \& awareness of } \\
\text { local neighbourhood cultures. }\end{array}$ \\
\hline \multicolumn{2}{|l|}{$\begin{array}{l}\text { - Compatibility, harmony } \\
\text { with other cultures. }\end{array}$} \\
\hline Psychological states & $\begin{array}{l}\text { - Legislation (venue/host } \\
\text { responsibility, responsible gambling } \\
\text { features, bans), }\end{array}$ \\
\hline $\begin{array}{l}\text { - Co-morbid mental } \\
\text { disorders, }\end{array}$ & $\begin{array}{l}\text { Screening people with co-morbid } \\
\text { disorders for gambling problems, }\end{array}$ \\
\hline $\begin{array}{l}\text { - Substance use with } \\
\text { gambling (tobacco, } \\
\text { alcohol, drugs), }\end{array}$ & $\begin{array}{l}\text { - Increased knowledge \& awareness } \\
\text { about risks of using gambling as a } \\
\text { coping mechanism, }\end{array}$ \\
\hline - Stress, & $\begin{array}{l}\text { - Developing, publicising \& } \\
\text { promoting alternative but } \\
\text { appropriate coping strategies. }\end{array}$ \\
\hline
\end{tabular}

Aims/targets for reducing risk factors

- Grief \& loss.

Aim to identify \& promote effective strategies, programs \& treatment that act as protection, a buffer, in ameliorating negative psychological states.

Agent (Gambling products \& services)

$\begin{array}{ll}\text { Exposure, availability \& } & \text { - } \\ \text { access to } & \text { within authentic Aboriginal } \\ & \text { philosophies, \& culture, } \\ \text { - Traditional gambling } & \text { - } \\ & \text { on trading modern rules of play based } \\ \text { - Commercial gambling } & \text { Developing \& promoting culturally } \\ & \text { appropriate responsible gambling } \\ & \text { strategies with \& for Aboriginal } \\ & \text { gamblers, } \\ \text { - } & \text { Legislation (venue/host } \\ & \text { responsibility, culturally appropriate }\end{array}$

Aim to guide the development of culturally effective information for gamblers on practices \& strategies that prevent the development of gambling-related problems with any gambling product or service. 
Table 1 (continued)

\begin{tabular}{|c|c|c|}
\hline Risk factors & Potential modifications & Aims/targets for reducing risk factors \\
\hline $\begin{array}{l}\text { Preferences for } \\
\text { continuous gambling } \\
\text { forms }\end{array}$ & $\begin{array}{l}\text { responsible gambling features \& } \\
\text { counselling), } \\
\text { - Increasing awareness, information \& } \\
\text { practical education about gambling } \\
\text { products \& chances of winning. }\end{array}$ & \\
\hline Gambling marketing & $\begin{array}{l}\text { - Undertake a socio-economic analysis } \\
\& \text { publicly report the community } \\
\text { benefits \& costs from gambling } \\
\text { operations, }\end{array}$ & $\begin{array}{l}\text { Aim to see benefits outweigh costs of } \\
\text { gambling by providing genuine \& } \\
\text { accurate information to } \\
\text { communities. }\end{array}$ \\
\hline $\begin{array}{l}\text { - Gambling operations } \\
\text { funding community } \\
\text { projects, } \\
\text { - Use of cultural icons. }\end{array}$ & $\begin{array}{l}\text { - Legislation \& industry codes of } \\
\text { conduct restricting marketing of } \\
\text { cultural representations associated } \\
\text { with gambling. }\end{array}$ & \\
\hline \multicolumn{3}{|c|}{ Environment (Family, friends, community) } \\
\hline Families \& friends & $\begin{array}{l}\text { Drawing on local cultural \& family } \\
\text { networks to create practical low-risk/ } \\
\text { social gambling strategies, }\end{array}$ & $\begin{array}{l}\text { Aim to support gamblers, families and } \\
\text { friends with information } \& \\
\text { education about gambling impacts }\end{array}$ \\
\hline $\begin{array}{l}\text { - Intergenerational } \\
\text { gambling norms, }\end{array}$ & $\begin{array}{l}\text { Increased awareness \& knowledge } \\
\text { about impacts of gambling, about } \\
\text { self-help for gamblers \& sources of } \\
\text { help for others, }\end{array}$ & and sources of heln \\
\hline $\begin{array}{l}\text { - High risk parental } \\
\text { gambling, } \\
\text { - Gambler friends }\end{array}$ & $\begin{array}{l}\text { Publicising links between high risk } \\
\text { gambling \& poverty in protection \& } \\
\text { prevention messages. }\end{array}$ & \\
\hline Adolescents & $\begin{array}{l}\text { - Integrating gambling education \& } \\
\text { help into other school resources } \\
\text { targeting high risk behaviour } \\
\text { reduction, }\end{array}$ & $\begin{array}{l}\text { Aim to educate adolescents, teachers } \\
\& \text { concerned others about gambling } \\
\text { risks \& attempt to reduce these risks. }\end{array}$ \\
\hline - High risk behaviours & $\begin{array}{l}\text { - Early intervention programs, } \\
\text { - In-depth gambling information for } \\
\text { teachers, parents \& peers }\end{array}$ & \\
\hline $\begin{array}{l}\text { - Reservation \& remote } \\
\text { location, } \\
\text { - Urban location. }\end{array}$ & $\begin{array}{l}\text { - Increased awareness \& knowledge } \\
\text { about impacts of gambling, about } \\
\text { self-help for gamblers \& sources of } \\
\text { help for others, } \\
\text { - Developing alternative but engaging } \\
\text { activities, } \\
\text { - Indentify unique issues facing people } \\
\text { in urban centres \& to publicise or } \\
\text { develop cultural \& economic } \\
\text { support systems to encourage social } \\
\text { inclusion, } \\
\text { - To provide information, protection \& } \\
\text { prevention programs on coping. }\end{array}$ & $\begin{array}{l}\text { Aim to reveal differences between } \\
\text { reservation \& urban communities \& } \\
\text { target their distinctive gambling } \\
\text { issues with appropriately developed } \\
\text { public health strategies. }\end{array}$ \\
\hline
\end{tabular}

Adapted from Perese et al. (2005)

Taking a public health approach means addressing the harms caused by gambling and experienced by individuals and at-risk groups of gambling problems using communitybased interventions. Developing strategies to prevent this harm can include increasing public 
knowledge and awareness of gambling impacts and harms through appropriate media and public education. Such strategies could be aimed at Aboriginal people generally to raise understanding of general and culturally distinctive gambling impacts and to assist those who experience negative effects of gambling by a loved one or relative. Other strategies are needed to protect vulnerable groups from gambling-related harm. Working with neighborhood health, welfare, and community groups, appropriate social and cultural strategies tailored to meet local conditions can be developed to respond to these gambling-related harms with self-help, family and cultural support, screening, counseling, treatment, and other interventions. To promote informed and balanced attitudes to gambling, the need for public education, especially campaigns highlighting risk factors, although a challenging task to get right, will make effective progress with the active involvement of Aboriginal people. Aboriginal input to identify appropriate cultural philosophies, values and beliefs is absolutely essential for underpinning awareness and information messages about gambling risk factors. If, as Tonmyr and Blackstock (2010) assert, the strongest research is that which takes Aboriginal cultural contexts into account at every step and interprets the research based on its cultural and contextual validity, then a corollary is that the strongest public health strategies needs similar involvement.

Conflicts of Interest The authors declared no conflicts of interest with respect to the data, authorship and/or publication of this article.

Funding This project and subsequent authorship of this article was funded by the Ontario Problem Gambling Research Centre.

\section{References}

Abbott, M., \& Volberg, R. (2000). Taking the pulse on gambling and problem gambling in New Zealand: phase one of the 1999 National Prevalence Survey. Report number three of the New Zealand gaming survey. Wellington: Department of Internal Affairs.

Aboriginal Health \& Medical Research Council of NSW (AHMRC). (2007). Pressing problems, gambling issues and responses for NSW Aboriginal communities. Sydney: Author.

Alegría, A., Petry, N., Hasin, D., Liu, S.-M., Grant, B., \& Blanco, C. (2009). Disordered gambling among racial and ethnic groups in the US: results from the National Epidemiologic Survey on alcohol and related conditions. CNS Spectrums, 14(3), 132-142.

Altman, J. (1985). Gambling as a mode of redistributing and accumulating cash among Aborigines: a case study from Arnhem Land. In G. Caldwell, B. Haig, D. Sylvan, \& L. Sylvan (Eds.), Gambling in Australia (pp. 50-67). Sydney: Croom Helm.

American Psychiatric Association (APA). (2000). Diagnostic and statistical manual of mental disorders (4th ed.). Washington, DC: Author.

Australian Bureau of Statistics (ABS). (2011). Australian demographic statistics, June quarter 2011, Cat. no. 3101.0. Canberra: Author.

Australian Institute for Gambling Research and Labour and Industry Research Unit (AIGR/LIRU). (1996). Long term study into the impact of gaming machines in Queensland: An issues paper. The economic and social impact of gaming machines on Aboriginal and Torres Strait Islander communities in Queensland. Brisbane: QLD Department of Families, Youth and Community Care.

Belanger, Y. (2006). Gambling with the future: The evolution of Aboriginal Gaming in Canada. Saskatoon: Purich Pubishing Ltd. 
Belanger, Y. (2010). First Nations gaming as a self-government imperative: ensuring the health of First Nations problem gamblers. International Journal of Canadian Studies, 41(1), 13-36.

Belanger, Y. (2011). Introduction. In Y. Belanger (Ed.), First Nations gambling in Canada: Current trends and issues (pp. 2-7). Winnipeg: University of Manitoba Press.

Bellringer, M., Perese, L., Abbott, M., \& Williams, M. (2006). Gambling among Pacific Mothers Living in New Zealand. International Gambling Studies, 6(2), 217-235.

Bertossa, S., Miller, P., Chong, A., \& Harvey, P. (2010). Gambling in a remote Aboriginal setting - the good, the bad and the ugly. Aboriginal and Islander Health Worker Journal, 34(4), 10-12.

Binde, P. (2005). Gambling across cultures: Mapping worldwide occurrence and learning from ethnographic comparison. International Gambling Studies, 5(1), 1-27.

Blaszczynski, A., \& Nower, L. (2002). A pathways model of problem and pathological gambling. Addiction, 97(5), 487-499.

Brady, M. (2004). Regulating social problems: The pokies, the productivity commission and an aboriginal community, discussion paper No. 269/2004. Canberra: Centre for Aboriginal Economic Policy Research.

Breen, H. (2008). Visitors to Northern Australia: debating the history of indigenous gambling. International Gambling Studies, 8(2), 137-150.

Breen, H. (2012a). Risk and protective factors associated with gambling products and services: Indigenous gamblers in north Queensland. International Journal of Mental Health and Addiction, 10(1), 24-38. doi:10.1007/s11469-010-9296-z.

Breen, H. (2012b). Risk and protective factors associated with gambling consequences for Indigenous Australians in north Queensland. International Journal of Mental Health and Addiction, 10(2), 258272. doi:10.1007/s11469-011-9315-8.

Breen, H., Hing, N., \& Gordon, A. (2011). Indigenous gambling motivations, behaviour and consequences in Northern New South Wales, Australia. International Journal of Mental Health and Addiction, 9(6), 723739. doi:10.1007/s11469-010-9293-2.

Canadian Council on Social Development (CCSD). (2011). Social challenges: The well-being of aboriginal people. http://www.ccsd.ca/cpsd/ccsd/c ab.htm. Accessed 31 May 2012

US Census Bureau (2012). US POPClock Projection. US Census Bureau, Washington. http://www.census.gov/ population/www/popclockus.html. Accessed 31 May 2012.

Clarke, D., Tse, S., Abbott, M., Townsend, S., Kingi, P., \& Manaia, W. (2007). Reasons for starting and continuing gambling in a mixed ethnic community sample of pathological and non-problem gamblers. International Gambling Studies, 7(3), 299-313.

Clay, T. (2009). Measuring the impact of reservation gambling revenues on Native American educational achievement. Journal of Public Budgeting, Accounting, and Financial Management, 21(1), 58-82.

Conner, T., \& Taggart, W. (2009). The impact of gaming on the Indian Nations in New Mexico. Social Science Quarterly, 90(1), 50-70.

Costello, E., Compton, S., Keeler, G., \& Angold, A. (2003). Relationships between poverty and psychopathology: a natural experiment. Journal of the American Medical Association, 290(15), 2023-2029.

Cozzetto, D., \& Larocque, B. (1996). Compulsive gambling in the Indian community: a North Dakota case study. American Aboriginal Culture and Research Journal, 20(1), 73-86.

Culin, S. (1907). Games of the North American Indians. New York: Dover.

Currie, C. (2007). The placement of casinos in Alberta's Aboriginal communities: An interview with Cheryl Currie. Gambling research reveals. Alberta Gaming Research Institute 7(1), 1-4.

Currie, C. (2011). How is problem gambling impacting urban Aboriginal Peoples? Banff: Alberta Gaming Research Institute Conference.

Currie, C., Wild, T., \& McKennitt, D. (2008). Exploring protective factors for addictive behavior among urban Aboriginal Canadians. Poster presentation for the CIHR-IAPH Global Indigenous Health Research Symposium, Victoria, BC.

Delfabbro, P., Lahn, J., \& Grabosky, P. (2005). Adolescent gambling: A report on recent ACT Research. Canberra: ACT Gambling and Racing Commission.

Derevensky, J., \& Gupta, R. (2004). Gambling problems in youth. The theoretical and applied perspectives. New York: Kluwer Academic Publishers.

Dickerson, M., Allcock, C., Blaszczynski, A., Nicholls, B., Williams, J., \& Maddern, R. (1996). A preliminary exploration of the positive and negative impacts of gambling and wagering on Aboriginal people in NSW. Sydney: Australian Institute of Gambling Research.

Dion, J., Collin-Vézina, D., De La Sablonnière, M., Philippe-Labbé, M., \& Giffard, T. (2010). An exploration of the connection between child sexual abuse and gambling in Aboriginal communities. International Journal of Mental Health and Addiction, 8, 174-189.

Dyall, L. (2004). Gambling: a social hazard. Social Policy Journal of New Zealand, 21, 22-40. 
Dyall, L. (2007). Gambling, social disorganisation and deprivation. International Journal of Mental Health and Addiction, 5, 320-330.

Dyall, L. (2010). Gambling: a poison chalice for indigenous peoples. International Journal of Mental Health and Addiction, 8, 205-213.

Dyall, L., \& Hand, J. (2003). Māori and gambling: why a comprehensive Māori Public Health response is required in New Zealand. International Journal of Mental Health \& Addiction, 1(1). published online September 15, 2003.

Dyall, L., Tse, S., \& Kingi, A. (2009). Cultural icons and marketing of gambling. International Journal of Mental Health and Addiction, 7, 84-96.

Dyall, L., Hawke, Z., Herd, R., \& Nahi, P. (2012). Housework metaphor for gambling public health action: An indigenous perspective. International Journal of Mental Health and Addiction. Published online 12 January 2012. http://www.springerlink.com/content/u17j1m0up8235231/fulltext.pdf. Accessed 23 July 2012.

Edmonds, P. (2010). Urbanizing frontiers: indigenous peoples and settlers in 19th-century pacific rim cities. Vancouver: University of British Columbia Press.

Elia, C., \& Jacobs, D. (1993). The incidence of pathological gambling among Native Americans treated for alcohol dependence. International Journal of the Addictions, 28(7), 659-666.

Environics Institute. (2010). Urban Aboriginal peoples study. Toronto: Environics Institute.

Ferris, J., \& Wynne, H. (2001). The Canadian problem gambling index: Final report. Ottawa: Canadian Centre on Substance Abuse.

First Nations of Québec and Labrador Health and Social Services Commission (FNQLHSSC). (2006). First Nations Regional Longitudinal Health Survey 2002. Report on First Nations living in the communities. Québec: Author.

Gabriel, K. (1996). Gambler way: Indian gaming in mythology, history, and archaeology in North America. Boulder: Johnson Books.

Goodale, J. (1987). Gambling is hard work: card playing in Tiwi society. Oceania, 58(1), 6-21.

Hewitt, D. (1994). The spirit of Bingoland: A study of problem gambling among Alberta Native people. Edmonton: Nechi Training, Research and Health Promotion Institute, AADDAC.

Hewitt, D., \& Augur, D. (1995). Firewatch on First Nations adolescent gambling. Edmonton: Nechi Training, Research and Health Promotions Institute, AADDAC.

Hing, N., Breen, H., \& Weeks, P. (2002). Club management in Australia, administration, operations and gaming (2nd ed.). Sydney: Pearson Education.

Hoy, W., Norman, R., Hayhurst, B., \& Pugsley, D. (1997). A health profile of adults in a Northern Territory Aboriginal community, with an emphasis on preventable morbidities. Australian and New Zealand Journal of Public Health, 21(2), 1-21.

Hunter, E. (1993). Aboriginal health and history, power and prejudice in remote Australia. Cambridge: Cambridge University Press.

Hunter, E., \& Spargo, R. (1988). What's the big deal? Aboriginal gambling in the Kimberley region. The Medical Journal of Australia, 149, 668-672.

International Work Group for Indigenous Affairs (2008). Declaration on the rights of Indigenous People. Retrieved 31 May 2012, from: http://www.iwgia.org/sw248.asp.

Jacobs, D. (1986). A general theory of addictions: a new theoretical model. Journal of Gambling Studies, 2, 15-31.

Joukhador, J., MacCallum, F., \& Blaszczynski, A. (2003). Differences in cognitive distortions between problem and social gamblers. Psychological Reports, 92(3, Pt. 2), 1203-1214.

Joukhador, J., Blaszczynski, A., \& MacCallum, F. (2004). Superstitious beliefs in gambling among problem and non-problem gamblers: preliminary data. Journal of Gambling Studies, 20(2), 171-180.

Korn, D., \& Shaffer, H. (1999). Gambling and the health of the public: adopting a public health perspective. Journal of Gambling Studies, 15(4), 289-365.

Lee, K. (2000). Urban poverty in Canada: A statistical profile. Ottawa: Canadian Council on Social Development.

Martin, D. (1993). Autonomy and relatedness: An ethnography of Wik people of Aurukun, Western Cape York Peninsula. Unpublished PhD thesis. Canberra: Australian National University.

Martin, D. (2008). Aboriginal sorcery and healing, and the alchemy of Aboriginal policy making'. Journal of the Anthropological Society of South Australia, 33, 75-128.

McDonald, H., \& Wombo, B. (2006). Indigenous gambling scoping study-Draft report. Darwin: School for Social and Policy Research, Charles Darwin University.

McGowan, V., \& Nixon, G. (2004). Blackfoot traditional knowledge in resolution of problem gambling: getting gambled and seeking wholeness. Canadian Journal of Native Studies, 24(1), 7-35.

McGowan, V., Frank, L., Nixon, G., \& Grimshaw, M. (2001). Sacred and secular play in gambling among Blackfoot peoples of Southwest Alberta. In A. Blaszczynski (ed.), Proceedings of the 11th. National Association of Gambling Studies Conference. Sydney, pp 241-255. 
McMillen, J., \& Donnelly, K. (2008). Gambling in Australian indigenous communities: the state of play. Australian Journal of Social Issues, 43(3), 397-426.

McMillen, J., Marshall, D., Ahmed, E., \& Wenzel, M. (2004). 2003 Victorian longitudinal community attitudes survey. Melbourne: Victorian Gambling Panel.

Ministry of Health. (2009). A focus on problem gambling: Results of the 2006/07 New Zealand Health Survey. Wellington: Ministry of Health.

Ministry of Health. (2010). Preventing and minimising gambling harm: Six year strategic plan 2010/11-2015/ 16. Wellington: Ministry of Health.

Momper, S. (2010). Implications of American Indian gambling for social work research and practice. Social Work, 55(2), 139-146.

Morrison, L. (1999). The good and the bad times: Māori women's experiences of gambling in Rotorua. Unpublished Master's thesis. Hamilton, New Zealand: University of Waikato.

National Aboriginal Health Strategy Working Group. (1989). A national Aboriginal health strategy. Canberra: Department of Aboriginal Affairs.

Neal, P., Delfabbro, P., \& O’Neil, M. (2005). Problem gambling and harm: Towards a national definition. Melbourne: Gambling Research Australia.

Oakes, J., Currie, C., \& Courtney, D. (2004). Gambling and problem gambling in First Nations communities. Ontario: Ontario Problem Gambling Research Centre.

Papineau, E. (2009). Gambling problems in First Nations and Inuit Communities of Québec: A brief status report. Québec: Institut national de santé publique du Québec.

Parke, J., \& Griffiths, M. (2007). The role of structural characteristics in gambling. In G. Smith, D. Hodgins, \& R. Williams (Eds.), Research and measurement issues in gambling studies (pp. 217-249). Burlington: Academic.

Peacock, R., Day, P., \& Peacock, T. (1999). Adolescent gambling on a Great Lakes Indian Reservation. Journal of Human Behavior in the Social Environment, 2(1), 5-17.

Penfold, A., Hatcher, S., Sullivan, S., \& Collins, N. (2006). Gambling Problems and attempted suicide: Part11-alcohol abuse increases suicide risk. International Journal of Mental Health and Addiction, 4, 273-279.

Perese, L., Bellringer, M., \& Abbott, M. (2005). Literature review to inform social marketing and approaches, and behaviour change indicators, to prevent and minimise gambling harm. Wellington: Health Sponsorship Council.

Petry, N., Stintson, F., \& Grant, B. (2005). Comorbidity of DSM-IV pathological gambling and psychiatric disorders: results from the National Epidemiologic Survey on Alcohol and Related Conditions. The Journal of Clinical Psychiatry, 66, 564-574.

Productivity Commission (2010). Gambling. Canberra: Report no. 50.

Queensland Department of Corrective Services. (2006). Houses of cards, problem gambling, indigenous communities and corrections. Brisbane: Queensland Government.

Raylu, N., \& Oei, T. (2004). Role of culture in gambling and problem gambling. Clinical Psychological Review, 23(8), 1087-1114.

Responsible Gambling Council (2011). Gambling and the Aboriginal Community. Retrieved June 3 2012, from: http:/ www.responsiblegambling.org/docs/default-document-library/gambling-and-the-aboriginal-community. pdf?sfvrsn $=4$.

Salter, M. (1979). Games, goods, and gods: an analysis of Iroquoian gambling. Canadian Journal of Applied Sport Sciences, 4, 160-164.

Schissel, B. (2001). Betting against youth: the effects of socio-economic marginality on gambling among young people. Youth and Society, 32(4), 473-491.

Schluter, P., Bellringer, M., \& Abbott, M. (2007). Maternal gambling associated with families' food, shelter, and safety needs: findings from the Pacific Island families study. Journal of Gambling Issues, 19, 87-90.

Smith, G., Currie, C., \& Battle, J. (2011). Exploring gambling impacts in two Alberta Cree communities: A participatory action study. In Y. Belanger (Ed.), First Nations gambling in Canada: Current trends and issues (pp. 118-139). Winnipeg: University of Manitoba Press.

Statistics Canada. (2008). Aboriginal Peoples in Canada in 2006: Inuit, Metis and First Nations, 2006 Census. Ottawa: Statistics Canada (Cat. No. 97-558-XIE). http://www.statcan.gc.ca/bsolc/olc-cel/olc-cel? lang=eng\&catno=97-558-X. Accessed 15 June 2012.

Steane, P., McMillen, J., \& Togni, S. (1998). Researching gambling with Aboriginal people. Australian Journal of Social Issues, 33(3), 303-315.

Stevens, M., \& Young, M. (2009a). Betting on the evidence: Reported gambling problems among the Indigenous population of the Northern Territory. Australian and New Zealand Journal of Public Health, 33(6), 556-565.

Stevens, M., \& Young, M. (2009b). Independent correlates of reported gambling problems amongst Indigenous Australians. Social Indicators Research, 98(1), 147-166. 
Stinchfield, R., Cassuto, N., Winters, K., \& Latimer, W. (1997). Prevalence of gambling among Minnesota public school students in 1992 and 1995. Journal of Gambling Studies, 13(1), 25-48.

Thomas, S., \& Jackson, A. (2004). Influences on gambling behaviours and outcomes: a model for the design of effective interventions. Gambling Research, 16(2), 40-51.

Tonmyr, L., \& Blackstock, C. (2010). Commentary: indigenous health special issue. International Journal of Mental Health, 8, 135-144.

Tse, S., Dyall, L., Clarke, D., Abbott, M., Townsend, S., \& Kingi, P. (2012). Why people gamble: a qualitative study of four New Zealand ethnic groups. International Journal of Mental Health and Addiction. doi:10.1007/s11469-012-9380-7.

United Nations. (2009). State of the world's indigenous peoples. ST/ESA/328. Department of Economic and Social Affairs. New York: United Nations.

Volberg, R., \& Abbott, M. (1997). Gambling and problem gambling among Indigenous peoples. Substance Use \& Misuse, 32(11), 1525-1538.

Walker, S., Abbott, M., \& Gray, R. (2012). Knowledge, views and experiences of gambling and gamblingrelated harms in different ethnic and socio-economic groups in New Zealand. Australian and New Zealand Journal of Public Health, 36, 153-159. doi:10.1111/j.1753-6405.2012.00847.x.

Wardman, D., el-Guebaly, N., \& Hodgins, D. (2001). Problem and pathological gambling in North American Aboriginal populations: a review of the empirical literature. Journal of Gambling Studies, 17(2), 81-100.

Wātene, N., Thompson, K., Barnett, A., Balzer, M., \& Turinui, M. (2007). The impacts of gambling for Māori Communities: A national Māori collaborative approach. Auckland: Te Rūnanga o Kirikiriroa Trust Inc Pou Tuia Rangahau.

Westermeyer, J., Canive, J., Garrard, J., Thuras, P., \& Thompson, J. (2005). Lifetime prevalence of pathological gambling among American Indian and Hispanic American Veterans. American Journal of Public Health, 95, 860-866.

Westermeyer, J., Canive, J., Crosby, R., \& Thompson, J. (2006). Remission from Pathological Gambling among Hispanics and Native Americans. Community Mental Health Journal, 42(6), 537-553.

Westermeyer, J., Canive, J., Thuras, P., Thompson, J., Kim, S., Crosby, R., \& Garrard, J. (2008). Mental health of non-gamblers versus "Normal" gamblers among American Indian Veterans: a community survey. Journal of Gambling Studies, 24, 193-205.

Williams, R., \& Simpson, R. (2008). Promising practices in the prevention of problem gambling. Ontario: Ontario Problem Gambling Research Centre.

Williams, R., Wynne, H., Nixon, G., \& Frank, L. (2005). Using participatory action research to study Canadian Aboriginal gambling. Presentation at the 6th. European Conference on Gambling Studies and Policy Issues. Malmo, Sweden.

Williams, R., Stevens, R., \& Nixon, G. (2011). Gambling and problem gambling in North American Aboriginal People. In Y. Belanger (Ed.), First Nations gambling in Canada: Current trends and issues (pp. 166-194). Winnipeg: University of Manitoba Press.

Wood, R., \& Williams, R. (2009). Internet gambling: Prevalence, patterns, problems, and policy options. Ontario: Ontario Problem Gambling Research Centre.

Wynne Resources Ltd. (1996). Adolescent gambling and problem gambling in Alberta: Summary Report. Edmonton: Alberta Alcohol and Drug Abuse Commission.

Wynne, H., \& McCready, J. (2005). Examining gambling and problem gambling in Ontario Aboriginal communities. Ontario: Ontario Problem Gambling Research Centre.

Yanicki, S., Gregory, D., \& Lee, B. (2011). Gambling behaviours among Aboriginal peoples: Indigenous and critical socio-ecological perspectives. In Y. Belanger (Ed.), First Nations gambling in Canada: Current trends and issues (pp. 195-226). Winnipeg: University of Manitoba Press.

Young, M., Barnes, T., Stevens, M., Paterson, M., \& Morris, M. (2007). The changing landscape of Indigenous gambling in Northern Australia: Current knowledge and future directions. International Gambling Studies, 7(3), 327-343.

Zitzow, D. (1996a). Comparative study of problematic gambling behaviors between American Indian and non-Indian adolescents within and near a northern plains reservation. American Indian and Alaskan Native Mental Health Research, 7, 14-26.

Zitzow, D. (1996b). Comparative study of problematic gambling behaviors between American Indian and non-Indian adults in a northern plains reservation. American Indian Alaskan and Native Mental Health Research, 7, 27-41. 